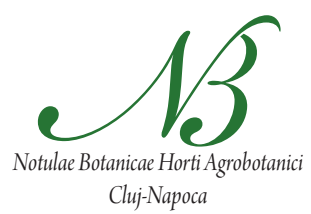

\title{
Positive Plant Diversity-Soil Stability Relationships are Mediated through Roots in the Songnen Grassland: Chronosequence Evidence
}

\author{
Liang-Jun $\mathrm{HU}^{1 *}$, Ping LI' ${ }^{1}$, Qinfeng $\mathrm{GUO}^{2}$ \\ ${ }^{1}$ Northeast Normal University, MOE Key Laboratory for Vegetation Ecology Science, 5268 Renmin Street, Life \\ Sciences Building, Changchun, Jilin 130021, China; hulj068@gmail.com ( ${ }^{*}$ corresponding author) \\ ${ }^{2}$ USDA FS, Eastern Forest Environmental Threat Assessment Center, 200 WT Weaver Blvd., Asheville, NC 28804, USA
}

\begin{abstract}
Living plant diversity (excluding the litter issue) may affect below-ground properties and processes, which is critical to obtaining an integrated biodiversity-ecosystem functioning theory. However, related patterns and underlying mechanisms have rarely been examined, especially lacking long-term evidence. We conducted a factorial crossed sample survey to examine the effects of plant diversity on soil stability over succession based on space-for-time substitution in the Songnen Steppes, North-Eastern China. The results indicate that, under natural colonizing conditions, species-poor systems achieved lower soil stability than species-rich systems, regardless of successional stage. However, soil stability was significantly regulated by plant species richness (number), composition (identity), density (abundance), and functional roles. Our results confirm that a long-term positive plant diversity-soil stability relationship exists in steppe succession. In particular, this enhanced effect of biodiversity on soil stability may operate via diversifying plant root traits. Our results may underpin an integrated biodiversity-ecosystem functioning theory, and improve human use and conservation management of natural resources at an integrated ecosystem level.
\end{abstract}

Keywords: biodiversity-ecosystem functioning, density compensation, diversity-stability relationship, functional role, mechanism, soil detachment rate, succession, root form

\section{Introduction}

The past two decades have seen extensive research in ecology on biodiversity and ecosystem functioning (BEF), as ecologists strive to estimate the consequence of widespread biodiversity loss while confronting the growing dominance of ecosystems much-altered by humans (Loreau, 2000; Loreau et al., 2001; Schwartz et al., 2000; Hooper et al., 2005; Maestre et al., 2012; Yang et al., 2012). Specifically, pursuing the relationships between biodiversity and ecosystem stability (BSR) has fascinated ecologists over an even longer history (Tilman, 1999; McCann, 2000; Tilman et al., 2006; Isbell et al., 2009; Haddad et al., 2011). For instance, the earlier campaign arose directly from the 'diversity-stability hypothesis' that greater diversity begets stability (MacArthur, 1955; Elton, 1958), but could be traced back to Darwin (Loreau, 2000; Hector and Bagchi, 2007). However, this has never been an easy task - the BSR patterns obtained have been multiple and contentious. Moreover, 'different theoretical results contradict each other, empirical results are inconsistent, and theoreticians and empiricists often disagree' (Ives and Carpenter, 2007). To date, the reached consensus has indicated that fully understanding the strength and pattern of BSRs not only requires detailed knowledge of species interactions and the impacting environmental contexts, but also of the multiplicity or multifacetedness of definitions of both biodiversity and stability (Pimm, 1984; McCann, 2000; Ives and Carpenter, 2007). Moreover, to better understand the BSRs and ecosystem management, investigating the underlying mechanisms may be more valuable (Ives and Carpenter, 2007).

The most relevant and frequently used terms of community/ecosystem stability include variability (e.g. the prevailing coefficient of variance based measures), resistance, invasibility, and resilience, respectively (Ives and Carpenter, 2007). Temporal stability (pertaining to the variability school), which has been defined as a lack of fluctuations over time and is usually calculated from measurements of biomass (Tilman, 1999; Isbell et al., 2009), cover (Sankaran and McNaughton, 1999; Dovciak and Halpern, 2010; Yang et al., 2012), or abundance/density (Valone and Hoffman, 2003), has often been addressed. While not without exceptions (Bezemer and van der Putten, 2007; Sasaki and Lauenroth, 2011), a major positive BSR relationship tends to occur at the community level (Tilman, 1996; Lehman and Tilman, 2000), but intense debates concentrate at the population level (Valone and Hoffman, 2003; Dovciak and Halpern, 2010; Yang et al., 2012). For example, although the population stability of individual species can have negative, neutral or positive relationships with diversity (van Ruijven and Berendse, 
2007), negative BSR patterns of populations of individual species seem to predominate in experimental grassland communities (Tilman et al., 2006; van Ruijven and Berendse, 2007), whereas positive or neutral relationships have been observed in natural assemblages (Valone and Hoffman, 2003; Romanuk et al., 2009). Exceptions are more common in other schools of stability, e.g., there is a dispute as to the role of 'insurance hypothesis' in maintaining the stability (resistance) of ecosystem functions and services provision (Pfisterer and Schmid, 2002; Valone and Barber, 2008).

In general, BSRs have been studied in three ways: above-ground versus above-ground, below-ground versus below-ground, and above-ground versus below-ground (Wardle et al., 2004). However, most of the experiments have concerned the effects of plant diversity on aboveground primary production or nutrient retention in grasslands during limited periods of time, often failing to detect significant effects on below-ground processes (Loreau et al., 2001) or long-term ecosystem consequences. Although below-ground BEFs (e.g. Hedlund and Ohrn, 2000; Heemsbergen et al., 2004; Wilson et al., 2009) and mutualistic linkages between above- and below-ground subsystems such as the effect of plant litter diversity on soil properties/decomposition (Wardle et al., 1997; Bardgett and Shine, 1999) or below-ground biodiversity effects on above-ground traits (van der Heijden et al., 2008; Wagg et al., 2011) have been examined substantially, the effects of living plant diversity on below-ground ecosystem properties and processes and underlying mechanisms have not been well understood (Bever, 1994; Loranger-Merciris et al., 2006; Wardle, 2006; Orwin et al., 2010; Sylvain and Wall, 2011). In particular, Jiang et al. (2008) suggest that diverse BEF relationships are possible for non-biomass functions due to negative selection effects. Moreover, little is known about how and why BSRs may vary over successional time (Dovciak and Halpern, 2010); the sufficiently long term evidence is lacking. All these invite more empirical evidence to enhance the assumption for resolving the dilemma.

Theory predicts that diversity can regulate community stability through mechanisms such as overyielding, the covariance effect (complementarity), and the portfolio effect (statistical averaging) (e.g. Doak et al., 1998; Tilman, 1999; Lehman and Tilman, 2000). The insurance hypothesis' has also been regarded as a critical mechanism (Yachi and Loreau, 1999). Furthermore, recent empirical studies have also indicated a sampling effect (e.g. Sasaki and Lauenroth, 2011), where stability was regulated by dominant species rather than diversity. Jiang (2007) suggests that, in competitive communities, diversity may not affect ecosystem functioning due to density compensation. However, under current consensus (Ives and Carpenter, 2007), it is most likely that more, not necessarily mutually exclusive, mechanisms are to be unravelled. For example, soil aggregation enhancement through enriched arbus- cular mycorrhizal fungi (AMF) may be a mechanism for increasing sequestration of carbon (Rillig, 2004; Rillig et al., 2007; Wilson et al., 2009). The interspecific functional dissimilarity may be another mechanism through which below-ground biodiversity drives soil processes (Heemsbergen et al., 2004).

The interplay between organisms and their physicchemical environment plays a key role in both evolution and ecosystem functioning (Loreau, 2010), and plants can affect soil processes either directly or indirectly (Loreau $e t$ al., 2001; Sylvain and Wall, 2011). Here, we conducted this study to examine the effects of above-ground living plant diversity upon below-ground ecosystem stability in natural steppe communities in northeastern China. To separate the effects of organisms and their physic-chemical environment, we assigned study plots that have relatively homogenous matrix conditions within a localized small area (no more than $100 \mathrm{ha}$ ). Here, we focus on one type of stability (i.e., soil aggregate stability) and four components of biodiversity (species richness, identity or composition, density or abundance, and functional traits). We assessed soil stability based on soil detachment rates (SDR; See De Baets et al., 2007), i.e., soil resistance to water dispersion as a function of perturbation. Higher SDR values indicate lower stability, and vice versa. The steppe represents the typical local vegetation along the eastern part of the Eurasian Steppes, the world's largest grassland biome, which has undergone intensifying perturbations and is shrinking (Wang et al., 2009). However, under changing diversity conditions during succession, the pattern and mechanism of a living plant diversity-soil stability relationship has yet to be investigated. Hence we attempt to address the following three questions: (1) what is the relationship between living plant diversity and soil stability in native steppe communities over successional cycles? (2) what plant community traits determine soil stability in steppe ecosystems? (3) what are the mechanisms that maintain plant diversity-soil stability relationships?

\section{Materials and methods}

\section{Study site}

The fieldwork was conducted on July 9, August 14, and September 11, 2010 in the northern steppe $\left(44^{\circ} 35^{\prime} \mathrm{N}\right.$, $\left.123^{\circ} 30^{\prime} \mathrm{E}\right)$, Northeast Normal University Changling Grassland Ecology Research Station, Jilin Province, China. The study site is a 100 ha fenced area within a Natural Reserve for grassland conservation established during the 1960s. The area has a monsoon climate with a long-term mean annual precipitation of about $470 \mathrm{~mm}$ ( $85 \%$ of which occurs in June - September). Mean annual temperature is about $4.6^{\circ} \mathrm{C}$ and average monthly temperatures range from $-17.6^{\circ} \mathrm{C}$ in January to $21.7^{\circ} \mathrm{C}$ in July. The soil is meadow soil, although zonally it is Chernozem. The vegetation is temperate steppe dominated by Stipa baicalensis, a species becoming increasingly rare owing to historical 
628

steppe-cropland conversion. Nevertheless, the widespread reclusive saline-alkali soils plus complex micro-topology create an abundance of non-zonal meadow steppes - Leymus chinensis, a rhizome grass species dominating meadows (Wang et al., 2009), emerging as the edaphic climax indication in the steppes.

About 357 grass species have been recorded that form the native $L$. chinensis-dominated associations at the site, although no fewer than 750 grass species have been reported in the steppes (Li, 2011). In the past, due to irrational land uses such as overgrazing and steppe-cropland conversion, steppe degradation was common. Three major stages of succession, either progressive or converse, can be readily identified and verified as follows: the $L$. chinensis monospecific community in late succession, mature and stable; mixed communities dominated by L. chinensis and others in transitional succession, with less stability; and communities dominated mainly by annual herbs like Suaeda glauca or Chloris virgata in the early colonizing stage, often heavily degraded and unstable. Since 2001, the initiation and ongoing implementation of the Grain for Green Project (GGP) has generated a continuing recovery effect in the steppes (Cao, 2011). Many steppes, by excluding grazing and cultivation, are thus in the process of progressive succession during natural restoration. The succession series often run in the following sequence: bare land $\rightarrow S$. glauca or C. virgata dominated community $\rightarrow L$. chinensis + Artemisia anethifolia or S. corniculata or C. virgata or Puccinellia tenuiflora or Hordeum brevisubulatum or Convolvulus ammannii or Allium polyrrbizum dominated communities $\rightarrow L$. chinensis + Carex duriuscula or A. neriniflorum or Cleistogenes squarrosa dominated communities $\rightarrow L$. chinensis or $L$. chinensis + weeds or Lathyrus quinquenervius or Thalictrum simplex or Galium verum or Eleocharis intersita or Potentilla flagellaris dominated communities (Li and Guo, 2011).

\section{Experimental design}

Our design was based on the diversity-time hypothesis that plant species diversity is always a transitional property changing with community successions (Ricklefs, 2007). In view of criticisms regarding the use of experimental communities (Jiang et al., 2009) including the uncertainty about the actual length of typical succession cycles in long-term experiments, we chose space-for-time substitution to build steppe successional chronosequences based on indicator species and community composition expertise in local steppe succession (Pickett, 1989; Li and Guo, 2011). The field design thus emerged was a factorially crossed sample survey upon the defined chronosequences. Biodiversity here was broadly defined, including terms that are numerical (both richness and density), compositional (identity), and functional. Because of the regularity in definition and nature of measuring functional diversity (Mouillot et al., 2005), we measured the functional roles of the component plant species by examining their root life forms (architecture). Three root architectures were recognized, i.e., rhizomatous root, tap root, and fibrous root, which usually played respective roles in affecting soil properties and processes $(\mathrm{Li}, 2011)$. Therefore, changing plant diversity during succession meant a concomitant varying placement of proportionate root traits within a soil volume.

Four treatments were thus recognized regarding succession: mature stage (climax), transitional stage (mixtures), early colonizing stage (pioneer), and a referenced bare-land stage. The community density/abundance factor was discerned by dividing overall coverage and stem density into two levels: higher density (coverage $>0.7$ ) and lower density (coverage $<0.4$ ) (Tab. 1). As a result, seven $2 \mathrm{~m} \times 2 \mathrm{~m}$ plots were carefully selected and placed, each representing a combination of key stage and community density in the succession (including a reference plot). Three replicates for each treatment were also made.

\section{Vegetation sampling}

Plant cover was measured using a $1 \mathrm{~m} \times 1 \mathrm{~m}$ frame with equally distributed $2 \mathrm{~cm} \times 2 \mathrm{~cm}$ grids. During the measurement, the frame was placed above the canopy in each quadrat. The percent cover of the community was visually point estimated in all grids and summed across grids for each plot. Within each plot, species richness was recorded as the number of plant species, and the species composition, including both species identity and abundance (i.e., the number of plant stems of each species) were also recorded). Compositions were thus characterized with regard to the dominant species (one or more) with higher abundance. This facilitated calculation of the functional weight of some species groups by linking their aboveground abundance and below-ground placement of root forms (Tab. 1).

\section{Soil sampling and stability test}

After the vegetation survey, the above-ground biomass was cleared by hand clipping such that intact soil sampling could be performed using rectangular polymer soil sample boxes (10 cm wide, $20 \mathrm{~cm}$ deep and $30 \mathrm{~cm}$ long; De Baets et al., 2011). The dispersal test apparatus consisted of a plastic basin ( $46 \mathrm{~cm}$ in diameter, $30 \mathrm{~cm}$ deep) and a metal sieve of appropriate diameter with $0.25 \mathrm{~mm}$ holes. Therefore, water-stable soil aggregates (WSA) were separated as microaggregates $(<0.25 \mathrm{~mm}$ in diameter) and macroaggregates $(>0.25 \mathrm{~mm}$ in diameter). Before the test, the sieve was placed in the basin, $10 \mathrm{~cm}$ above the basin bottom. The root permeated soil sample was put on the sieve in the basin, and tapwater was gently added to the basin without disturbing the soil sample until it was submerged. This spontaneous dispersal process lasted 4 hours. The metal sieve together with the remaining soil on it was then carefully removed from the basin; and the detached soil particles were separated from the undetached aggregates (defined as $>5 \mathrm{~mm}$ fractions) on the sieve and both 
Tab. 1. The characteristics in above- and below-ground communities at the study site

\begin{tabular}{|c|c|c|c|c|c|c|c|}
\hline Plot & Succession stage & $\begin{array}{c}\text { Plant } \\
\text { coverage }\end{array}$ & $\begin{array}{c}\text { Plant } \\
\text { diversity in } \\
\text { soil sample }\end{array}$ & Species composition & $\begin{array}{c}\text { Percentage } \\
\text { of species } \\
\text { present (\%) }\end{array}$ & $\begin{array}{l}\text { Stem density } \\
\text { (stems ha-1) }\end{array}$ & Root life-form \\
\hline \multicolumn{8}{|c|}{ Climax } \\
\hline 1 & Higher stem density & 0.8 & 1 & Leymus chinensis & 100 & $2,783,300$ & Rhizamatous root \\
\hline 2 & Lower stem density & 0.2 & 1 & L. chinensis & 100 & 695,830 & Rhizamatous root \\
\hline \multicolumn{8}{|c|}{ Transition } \\
\hline \multirow[t]{6}{*}{3} & Higher stem density & 0.9 & 6 & Phragmites communis & 30 & $1,000,000$ & Rhizamatous root \\
\hline & & & & Kalimeris integrifolia & 50 & $1,670,000$ & Rhizamatous root \\
\hline & & & & L. chinensis & 10 & 333,300 & Rhizamatous root \\
\hline & & & & Artemisia mongolica & 5 & 166,700 & Rhizamatous root \\
\hline & & & & Puccinellia tenuiflora & 4 & 133,332 & Fibrous root \\
\hline & & & & Cleistogenes squarrosa & 1 & 33,330 & Fibrous root \\
\hline \multirow[t]{5}{*}{4} & Lower stem density & 0.2 & 4 & P. communis & 25 & 173,750 & Rhizamatous root \\
\hline & & & & K. integrifolia & 65 & 451,750 & Rhizamatous root \\
\hline & & & & L. chinensis & 5 & 34,750 & Rhizamatous root \\
\hline & & & & A. mongolica & 5 & 34,750 & Rhizamatous root \\
\hline & Pioneer & & & & & & \\
\hline 5 & Higher stem density & 0.9 & 1 & Chloris virgata & 100 & $3,131,200$ & Fibrous root \\
\hline 6 & Lower stem density & 0.2 & 1 & C. virgata & 100 & 695,800 & Fibrous root \\
\hline 7 & Bare land & 0 & 0 & Bare soil & 0 & 0 & No \\
\hline
\end{tabular}

were weighted after air drying for 10 days. Detached soil passing through the sieve was also measured to obtain the microaggregate SDR. SDR was thus calculated as:

SDR $=$ Detached soil aggregates weight $/$ Tested soil sample weight $\times 100 \%$.

In this research, we measured three SDRs, i.e., abovesieve or water-stable macroaggregates SDR (ADR), belowsieve or microaggregates SDR (BDR), and the summed SDR (TDR). The soil stability was thus defined to be $1 /$ SDR, which emerged as a value without dimension and encompassed three stability measures, i.e., $\mathrm{AS}=\mathrm{ADR}^{-1}$ (macroaggregate stability), $\mathrm{BS}=\mathrm{BDR}^{-1}$ (microaggregate stability), and $\mathrm{TS}=\mathrm{TDR}^{-1}$ (overall stability).

\section{Root analyses}

After the soil dispersal test, for each soil sample, the roots were separated and treated and root variables such as root density (RD) and root length density (RLD) were measured following De Baets et al. (2011). Species identities and related root life forms were also considered, such that root measures of respective species, the dominant root-form, and their total were all readily available.

\section{Statistical analyses}

A data normality test was made and if weak, for the sake of maintaining the originality of data, data transformation was avoided by the use of a nonparametric method. Therefore, a multivariate General Linear Model (GLM) analysis was first applied to examine treatment ef- fects of successional stage and community plant density and their interactions on soil stability in a random-plot design. Since successional stage in effect includes 'hidden treatments' such as species richness and composition, we conducted a multivariate GLM analysis to further test the specific effects of community plant species richness, composition, density, and their interactions on soil stability. In addition, plant composition variation is usually associated with a proportionate change in diversifying root life forms within a soil volume. We thus conducted another GLM analysis to test the effects of species richness, density, rootforms, and their interactions on soil stability. A one-way ANOVA was also carried out to examine effects of species richness on soil stability. Student-Newman-Keuls (SNK-q) tests were used to discern the multiple means' grouping performance. To draw the BSR, we performed a regression analysis to fit the variations in diversity during succession and accompanying soil stability. To explore the underlying mechanisms for the observed BSR, a regression analysis was used to distil possible links between key root variables and concomitant soil stability. All the analyses were performed using SPSS 13.0 for Windows (SPSS Inc., 1989-2004, USA).

\section{Results}

Species richness variation and compositions during succession 
630

Our vegetation survey indicated that species richness increased drastically throughout succession, from 1 ( 3 in the plot) at the pioneer stage to about 5 (16 in the plot) at the transitional stage, and then decreased to 1 ( 3 in the plot) again at the climax stage (Fig. 1d; Tab. 1).

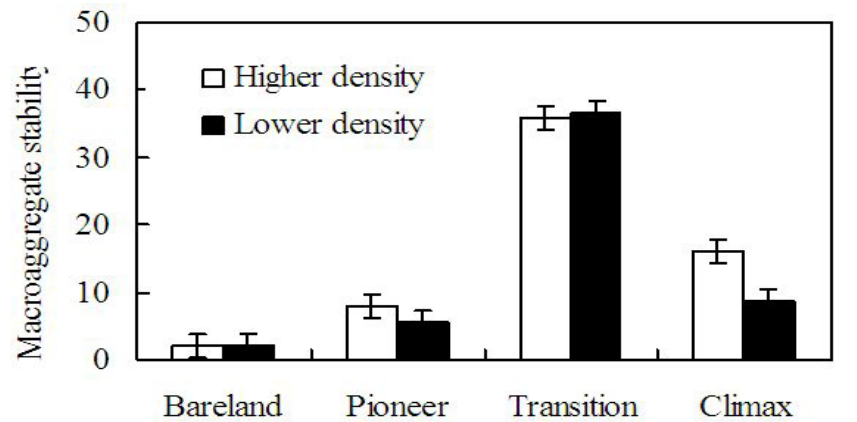

(a)

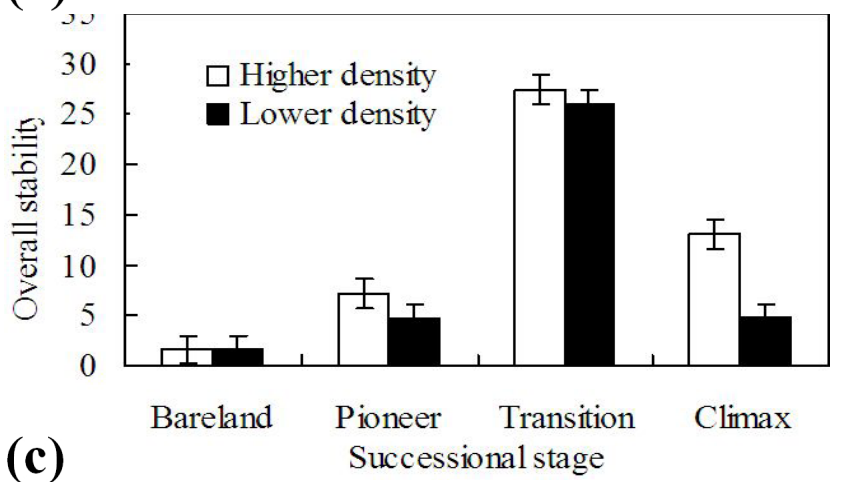

The referenced bare-land stage had the lowest soil stability, while the transitional stage had the highest, and both early and late successional stages exhibited intermediate levels of stability (Fig. 1a-c). In contrast, high plant density was related to greater soil stability (Fig. 1; Fig. 2).

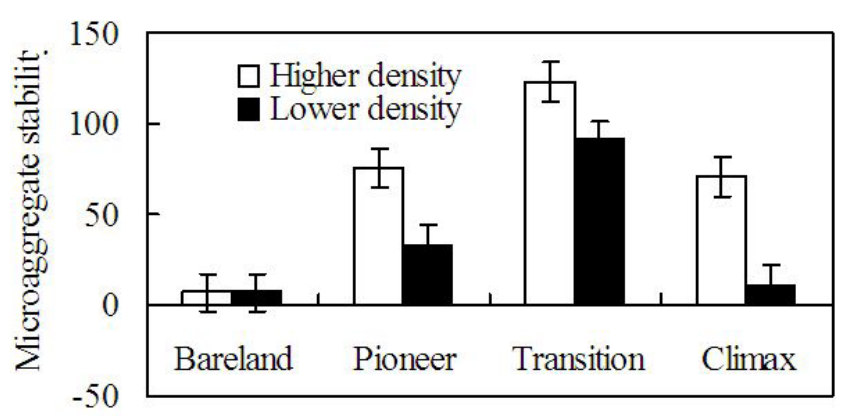

(b)

Successional stage

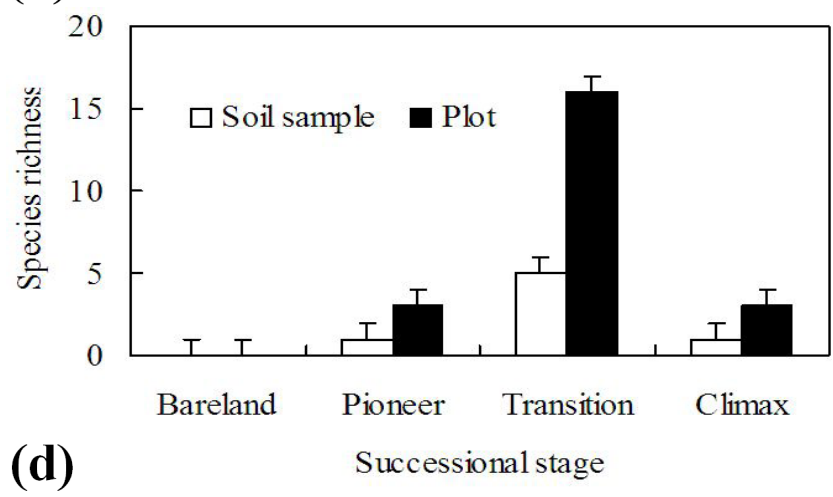

Fig. 1. Effects of successional stage and plant density on soil stability ( \pm SE). (a): macroaggregate stability (AS); (b): microaggregate stability (BS); (c): overall soil stability (TS); (d): species richness variations along successions

Also, plant community compositions evolved from early colonizing annual herbs (e.g. Chloris virgata) to complicated mixtures (annuals and perennials) and then to the climax-indicator dominated perennials (Tab. 1).

Effects of successional stage, species richness, composition, and plant density on soil stability

Multivariate GLM revealed that both successional stage and plant density had significant effects on all soil stability measures, i.e., microaggregate stability, macroaggregate stability, and overall soil stability, but no significant interactive effects $(\alpha=0.05$; Tab. 2, Fig. 1a-c).

Tab. 2. Effects of successional stage (ST), plant density (D), and their interactions on soil stability, using multivariate analysis of General Linear Model (GLM). DF is degrees of freedom

\begin{tabular}{ccccccccc}
\hline & & \multicolumn{2}{c}{ AS } & \multicolumn{2}{c}{ BS } & \multicolumn{2}{c}{ TS } \\
& df & F & P & F & P & F & P \\
\hline ST & 2 & 165.77 & $<.001$ & 21.19 & $<.001$ & 124.36 & $<.001$ \\
D & 1 & 4.49 & 0.052 & 25.89 & $<.001$ & 12.27 & 0.004 \\
\hline ST $\times$ D & 2 & 2.91 & 0.088 & 0.77 & 0.480 & 3.37 & 0.064 \\
\hline
\end{tabular}

However, plant density had a stronger effect on BS ( $p<$ $0.01)$ and TS $(\mathrm{p}<0.01)$ than on AS $(\mathrm{p}=0.052)$.

Further test results substantiated that the 'hidden treatments' of successional stage, e.g., species richness and composition, together with plant density, also had significant effects on soil stability, but still no interactive effects $(\alpha=$ 0.05; Tab. 3, Fig. 2a-f).

Tab. 3. Interactive effects of species richness (SP), composition (C) or root-forms (R) and plant density (D) on soil stability using multivariate GLM

\begin{tabular}{cccccccc}
\hline & \multicolumn{3}{c}{ AS } & \multicolumn{2}{c}{ BS } & \multicolumn{2}{c}{ TS } \\
& df & F & P & F & P & F & P \\
\hline SP & 1 & 190.72 & $<.001$ & 40.15 & $<.001$ & 173.65 & $<.001$ \\
\hline D & 1 & 3.34 & 0.089 & 24.04 & $<.001$ & 10.48 & 0.006 \\
\hline $\mathrm{C}(\mathrm{R})$ & 1 & 10.85 & 0.005 & 1.63 & 0.222 & 4.50 & 0.052 \\
$\mathrm{SP} \times \mathrm{D}$ & 1 & 2.236 & 0.154 & 0.927 & 0.350 & 1.942 & 0.183 \\
\hline $\mathrm{SP} \times \mathrm{C}(\mathrm{R})$ & 0 & & & & & & \\
$\mathrm{D} \times \mathrm{C}(\mathrm{R})$ & 1 & 2.06 & 0.173 & 0.61 & 0.449 & 4.00 & 0.065 \\
$\mathrm{SP} \times \mathrm{D} \times \mathrm{C}$ & & & & & & & \\
$(\mathrm{R})$ & & & & & & & \\
\hline
\end{tabular}




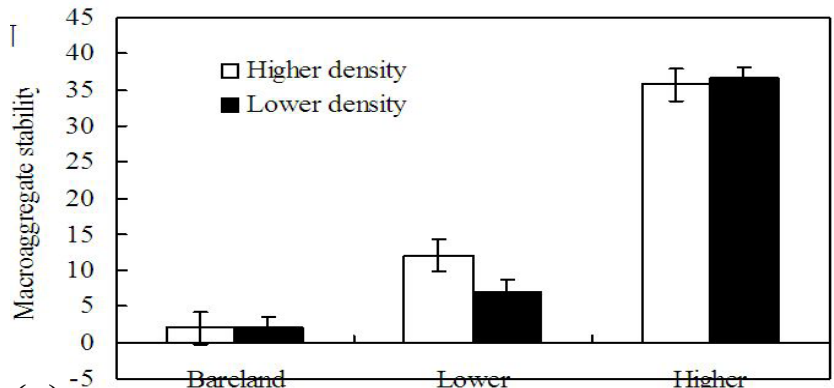

(a)

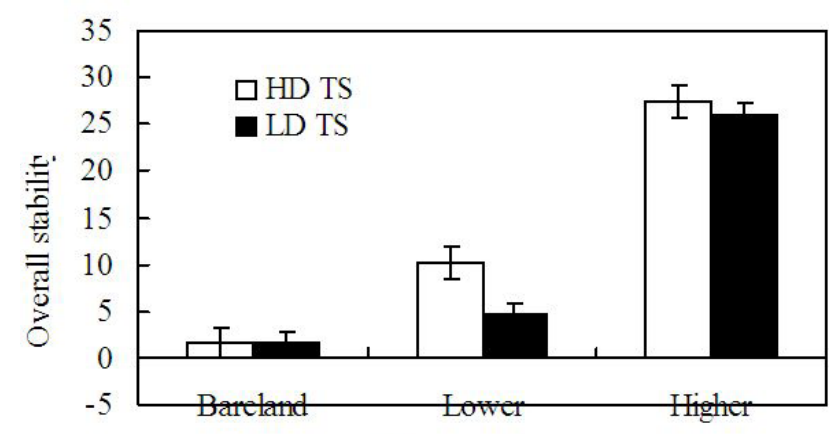

(c) Species richness

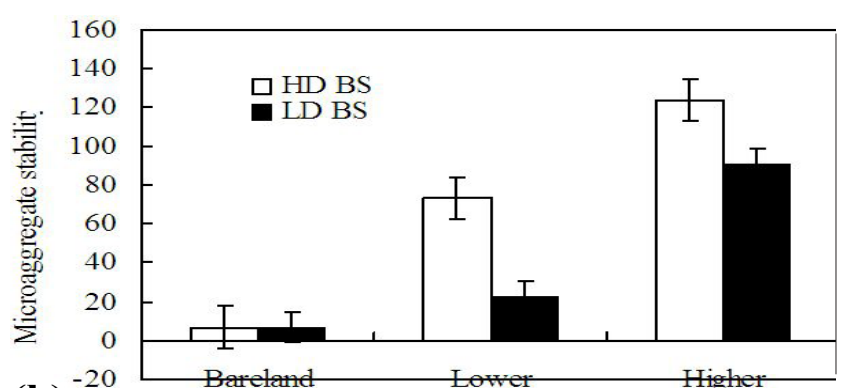

(b)

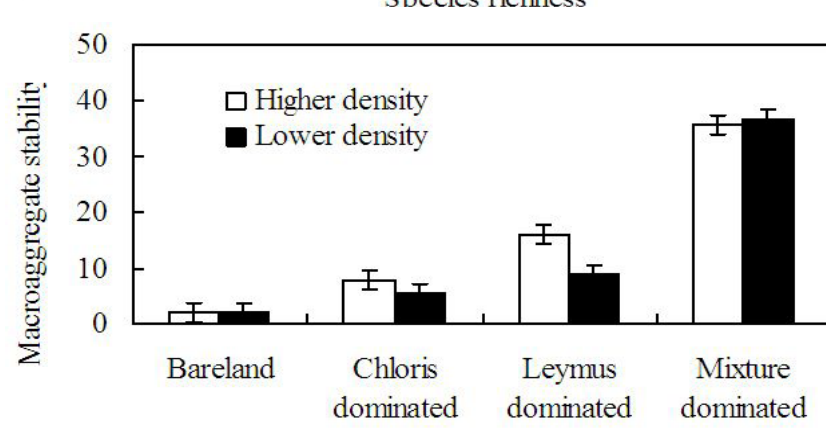

(d) Species composition

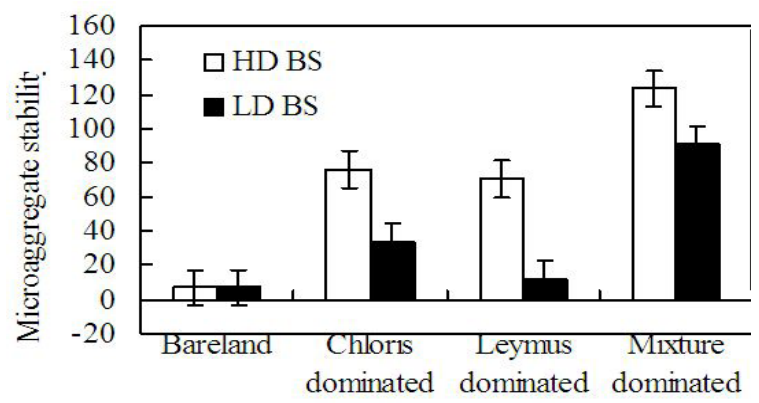

(e) Species composition

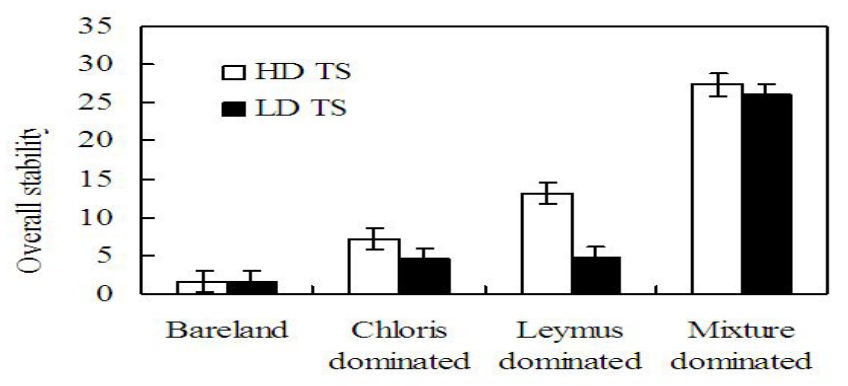

(f)

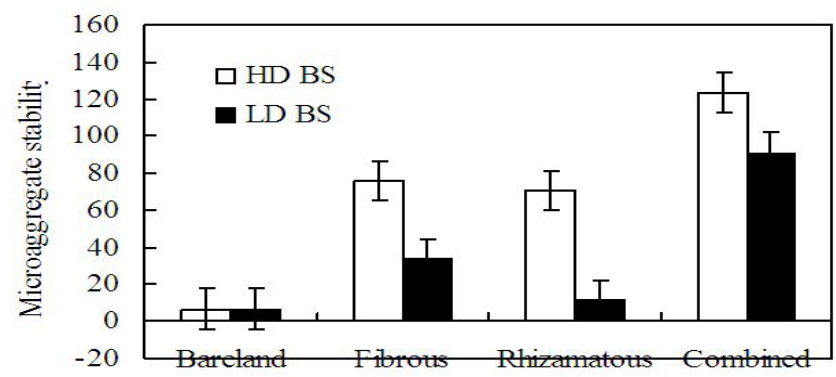

(h)
Root form

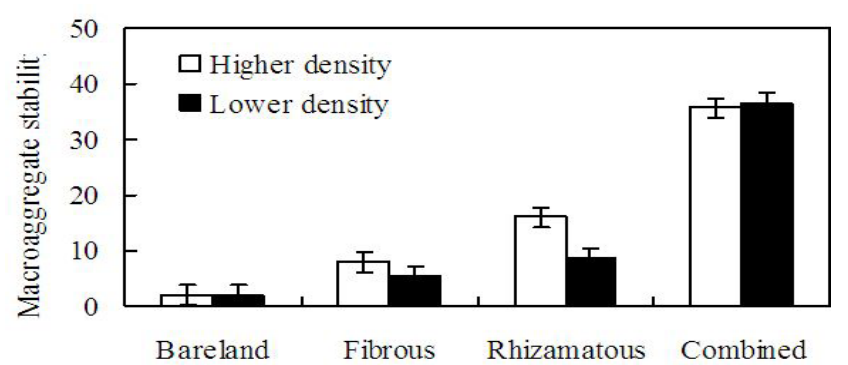

Root form

(g)

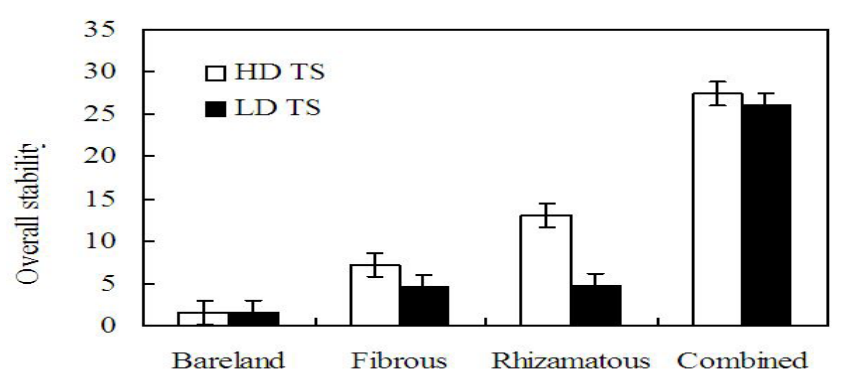

(i)

Root form

Fig. 2. Effects of species richness, composition and dominant root-form on soil stability ( \pm SE). See Fig. 1 for treatment abbreviations 
632

Species richness positively affected all three types of soil stability measures significantly $(\mathrm{p}<0.01)$ - speciesrich systems had higher soil stability than species-poor systems, whereas species composition had much stronger effects on AS $(\mathrm{p}<0.01)$ than on TS $(\mathrm{p}=0.052)$ but not on BS ( $p=0.222$; Tab. 3). Nevertheless, microaggregates appeared to be more stable than macroaggregates under all treatments, with generally higher BS values than AS or TS (Fig. 1; Fig. 2).

Diversity-stability relationship and possible mechanisms

Similar to the results for each successional stage, throughout the entire successional cycle, all three measures of soil stability also showed positive relationships with plant species richness (Fig. 3a-c). Root-soil stability analysis indicated that, with the changing direction of plant diversity during succession, plant root-form scenarios affected soil stability, consistent with the effect of species compositions (Tab. 3; Fig. 2g-i). In general, bare-land (no roots) had the lowest soil stability, while communities with combinations of fibrous-root- and rhizomatous-root species generated the highest soil stability, with intermediate performances seen for species with either solely fibrous roots or rhizomatous roots (Fig. $2 \mathrm{~g}-\mathrm{i}$ ).

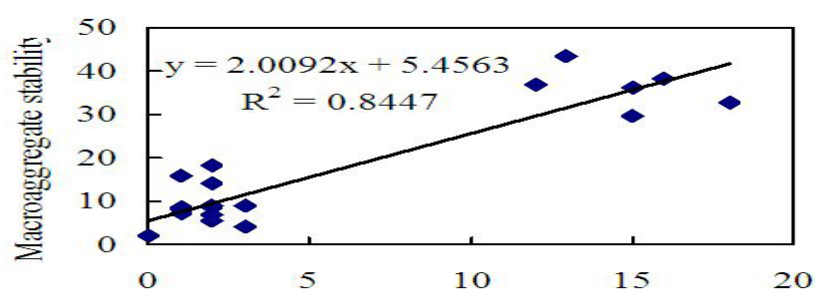

(a)

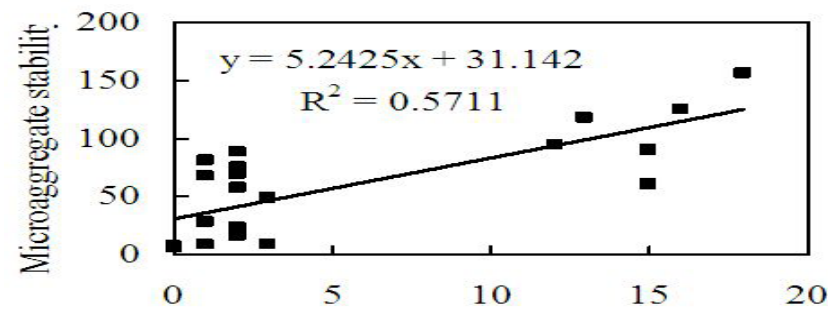

(b) $\mathrm{S}$ pecies richness

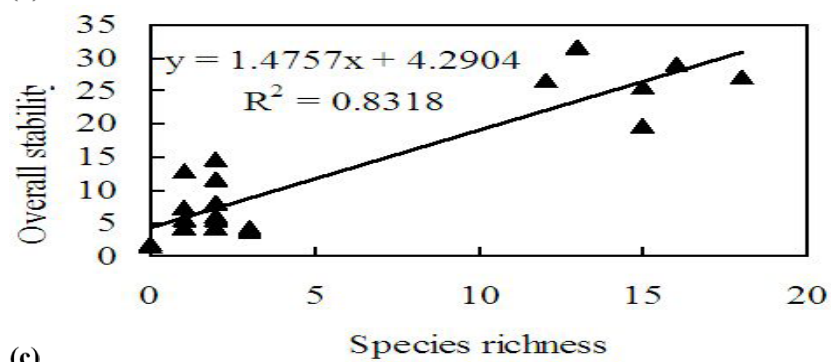

Fig. 3. The relationship between species richness and soil stability for macroaggregate stability (AS; a); microaggregate stability (BS; b); and overall soil stability (TS; c)
A further plant root-soil stability analysis corroborated that soil stability was positively correlated with both root density (RD) and root length density (RLD) (Fig. 4a-f). However, RD (biomass) showed a stronger correlation with soil stability than RLD (Fig. 4).

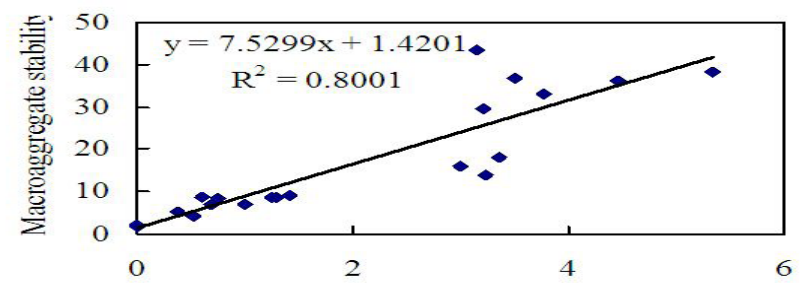

(a)

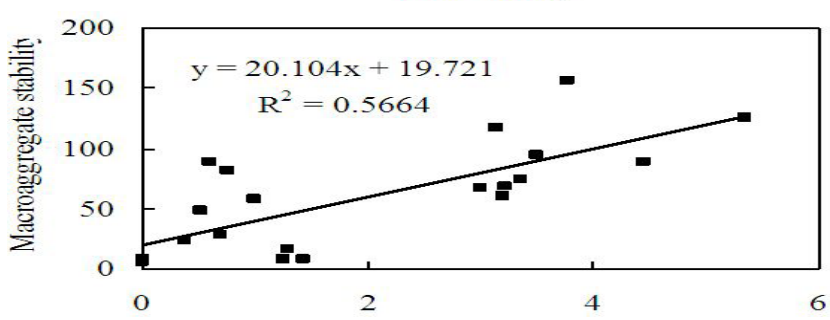

(b) Root density

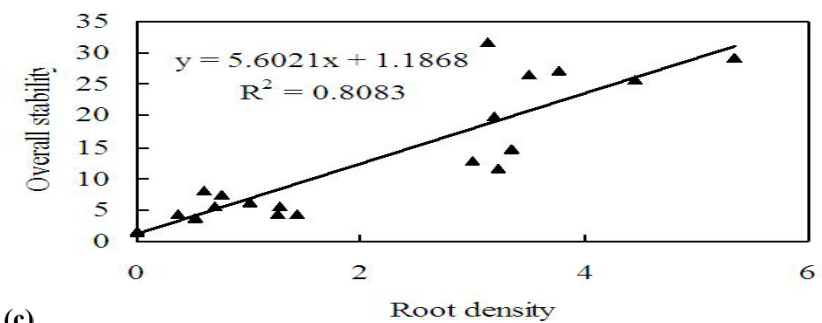

(c)

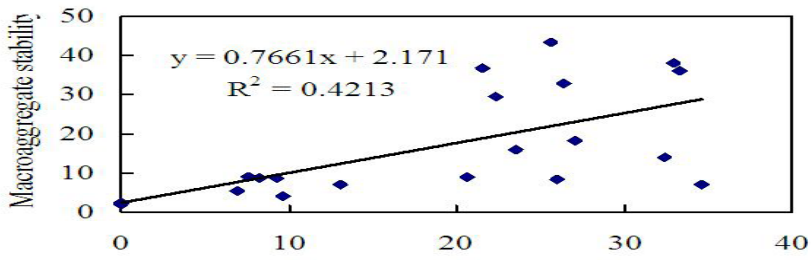

(d) Root length density
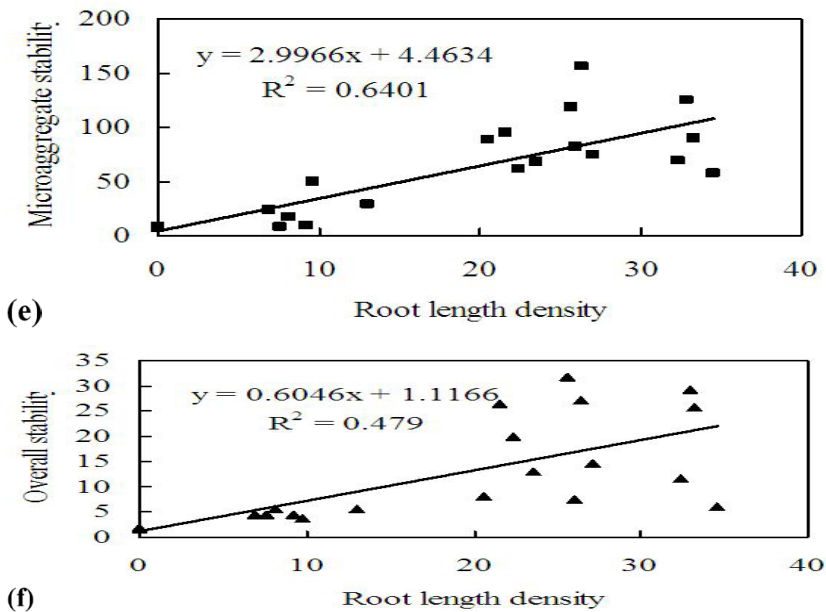

Fig. 4. The relationship between plant root and soil stability for macroaggregate stability (AS; a,d); microaggregate stability (BS; b, e); and overall soil stability (TS; c, f) 


\section{Discussion}

\section{Species richness and composition during succession}

Our results exhibit a general trend of changing plant species richness and associated community compositions in parallel with steppe succession, consistent with the diversity-time hypothesis (Ricklefs, 2007). This trend is also in line with other mainstream ecological theories, e.g., the succession theory (Peet and Christensen, 1980; Huston and Smith, 1987), the competition theory (Rajaniemi et al., 2003), and the climax hypothesis (Phillips, 1934). During the early colonizing phase of succession, growing conditions are usually harsh and plant growth is slow, which often results in long-term declines in plant species diversity (Cammeraat et al., 2005) and dominance of short-span early successional species, e.g., annual herbs. Moreover, these species may be better colonists but poorer competitors in the communities (Tilman et al., 2007). In contrast, during transitional stages from early to late succession, species richness tends to increase toward an acme, with intensifying resource use efficiency and species interactions during community assembly, exhibiting a tendency toward saturation of the communities. While in late succession, intense competitions and other evolutionary factors lead to a major exclusion effect and thus decline in species richness, finally generating the climax communities (Ricklefs, 2007). Meanwhile, in the course of succession, early successional species are replaced by more persistent species, e.g., perennial herbs or woody species, causing manifest variations in community species composition. Moreover, annual herbs with fibrous roots in the early stage were gradually replaced by perennial grasses with rhizomatous roots dominating the late successional stage, with a transitional period dominated by a mix of annuals and perennials with their own specific respective root-forms. Based on these findings, our results thus suggest that space-for-time substitution rather than permanent-plot experiments may indeed be a robust tool to facilitate long-term ecological studies, such as exploring long-term BSRs, in agreement with Foster and Tilman (2000).

What are the determinants of soil stability under changing plant diversity conditions during succession?

Soil stability, as measured by soil aggregate stability (resistance to disturbance) or fluctuating rates of other soil properties or processes (variability; e.g., Wardle et al., 2000; Wang et al., 2012), is an elementary component of ecosystem stability. It has been suggested that the mechanisms by which plants stabilize soil aggregates may be manifold (Pohl et al., 2009). First, the above-ground accumulated plant litter can increase carbon input (soil organic matter) in the soils through decomposition (Wardle, 2006; Sylvain and Wall, 2011), causing an enhanced soil aggregation process (Franzluebbers et al., 2000; Cammeraat et al., 2005). Second, the below-ground root systems may form anchors that can stabilize the loose soil (Gyssels and Po- esen, 2003; Pohl et al., 2009). Third, dead roots can also accumulate, thus increasing carbon input into the soil, as is often seen in higher productivity environments (Sylvain and Wall, 2011). Fourth, other above- and below-ground factors favouring rhizospheric activities will also favour soil aggregation by increasing glomalin, e.g., increased biomass production, higher AMF abundance (Wilson et al., 2009), or other enriched soil biodiversity conditions. In particular, all these may be found over successional phases (Dovciak and Halpern, 2010), an idea also borne out in our investigation. For example, vegetation successional stage has been reported to have progressively increasing effects on the population stability of forest herbs (Dovciak and Halpern, 2010). However, no vegetation successional effect has been observed on slope stability in abandoned lands (Cammeraat et al., 2005). Yet in our case, although successional stage had significant effects on soil stability, these effects did not exert themselves progressively over time (Fig. 1).

It has been further assumed that many factors attributable to successional stage or life history may play respective roles in regulating ecosystem stability (Dovciak and Halpern, 2010). First, higher plant diversity may indeed enhance soil stability. For example, Pohl et al. (2009) found that, in disturbed alpine ecosystems, plant diversity can enhance soil stability. Wang et al. (2012) also report that, in secondary succession in a semi-humid evergreen broadleaf forest, plant species richness can enhance soil conservation, although the effect may be relatively weak compared to the contributions of plant cover and density. In particular, plant functional richness may also exert effects on some below-ground properties in natural communities but not on the resistance to perturbation of any of the ecosystem properties considered in artificial communities (Wardle et al., 2000; see also Gastine et al., 2003 study in temperate grassland communities). In addition, litter diversity may not always support the view that enhanced species richness improves ecosystem functions (Wardle, 1997). Despite these debates, it is believed that ecosystem stability can be maintained if diversity has facilitative effects, or if stability is a precursor rather than a response to diversity (Dovciak and Halpern, 2010; see also Bai et al., 2004; Wang et al., 2012).

Second, however, the composition of the above-ground plant species (or the identity of a functional group) may affect the responses of below-ground properties to disturbance and thus affect ecosystem stability, albeit the relative effects of plant richness, composition and others are still disputed on occasion (Hooper and Vitousek, 1997; Tilman et al., 1997; Wardle et al., 2000; Wang et al., 2012).

Third, plant density may also affect ecosystem functioning (Jiang, 2007). However, density dependence may not be always prevalent, particularly in a highly heterogeneous ecosystem (Luo et al., 2012). Consistent at least in part with previous findings, our results stipulate that plant 
634

species richness, composition (also functional), and plant density simultaneously affect soil aggregate stability in the Songnen steppe.

Apart from the above, disturbance may also influence ecosystem stability either directly or indirectly through the richness, composition, or functions of the governing species. For instance, on some occasions mowing may increase population and community stability, and nutrient addition may have the opposite effect, but they do not alter the BSR patterns (Yang et al., 2012). However, grazing of pastures may have little detrimental effect on soil aggregate stability in the Southern Piedmont USA (Franzluebbers et al., 2000). By contrast, compared to other factors such as skiing in general, heavy disturbances like machine-grading on ski slopes can have strong effects on soil stability and species richness as well as on the BSRs in disturbed alpine ecosystems (Pohl et al., 2012). Therefore, vegetation factors, including species richness, cover, and root character, are more important for soil stability at machine-graded sites than at sites with little disturbance. In our study, disturbance has not been considered as a separate factor affecting soil stability, since one of our goals is to investigate the native Eurasian steppes subjected to no major anthropogenic perturbations over entire successional cycles. To investigate the likely effects of a specific disturbance on soil stability, new studies with specific field or experimental designs are needed. However, despite the difficulty of pinpointing all the factors affecting soil stability, and their likely intrinsic linkages among each other, our results suggest that the determinants of soil stability in relation to plant diversity are of multivariate sources operating over entire succession cycles.

\section{Positive diversity-stability relationships and underlying mechanisms}

Interestingly, the positive species richness-soil stability relationships observed in this study are in agreement with major theories that biodiversity begets stability (e.g. Doak et al., 1998; Tilman et al., 1998; Tilman, 1999; Lehman and Tilman, 2000) and many empirical studies including above-ground (e.g., Tilman and Downing, 1994; Tilman et al., 2006; Dovciak and Halpern, 2010; Allan et al., 2011), below-ground (e.g., Heemsbergen et al., 2004; Wilson et al., 2009; Wagg et al., 2011), and above- versus below-ground (e.g., Porazinska et al., 2003; Zak et al., 2003; Orwin et al., 2010; Eisenhauer et al., 2011) experiments. In particular, it is also consistent with the recent efforts on biodiversity-ecosystem multifunctionality relationships (Hector and Bagchi, 2007; Maestre et al., 2012). However, although the positive plant species richness - soil stability relationship is strong over the course of succession in our study, species richness is not the only major driver of soil stability and there is a definite cause-and-effect relationship. In our study, plant density, together with species richness and composition, all significantly affected soil stability, which is consistent with Wang et al. (2012). But the relative importance of species richness was greater than that of density and composition in affecting soil stability in our case. Therefore, compared to other efforts in solely above-ground or solely below-ground systems, our efforts linking above- and below-ground elements may reveal particular mechanisms governing plant diversity and soil stability relations. In this light, the positive plant species richness-soil stability relationships obtained throughout entire succession cycles in our study may only be a byproduct of multivariate co-working mechanisms of major plant community traits or others.

Unlike some theoretical interpretations trying to elucidate mechanisms for maintaining ecosystem stability (e.g. Tilman et al., 1998; Yang et al., 2012), we seek interpretations based on likely mechanistic pathways leading to the diversity-dependent stability of the steppe soils. Fortunately we found that, moving along the direction of succession, there is always some regular rhythmic fluctuation of soil stability in response to variations in species richness, community composition and plant density across successional stages (Figs. 1,2). This is because plant community succession often involves simultaneous changes not only in species richness (number), but also in species compositions (identity) and community density (abundance). Therefore, it would be very odd to relate species richness only to stability, when other diversity-related variables may also affect stability at the same time. In our research, with the variations in species richness with succession, speciespoor communities often have simple compositions and fewer root types with lower root biomass, while speciesrich communities have more complex compositions with mixed root types and higher root biomass (Tab. 1; Figs. 2, $3,4)$. To our knowledge, the enhanced root biomass and mixing of diverse root types in the communities can result in a positive relationship between soil stability and plant species richness (Pohl et al., 2009; Sylvain and Wall, 2011). In contrast, density compensation may be equally important for maintaining soil stability (Jiang, 2007). However, in some situations, density may actually override the effect of species richness-induced elements, posing a conversion of roles between species richness and density in governing richness-stability relationships.

\section{Conclusions}

We conclude as follows: (1) Under natural colonizing conditions in the Songnen Steppes, species-poor systems achieved lower soil stability than species-rich systems, regardless of successional stage; (2) Soil stability was dramatically regulated by plant species richness (number), composition (identity), density (abundance), and functional roles; (3) A long-term positive plant diversity-soil stability relationship exists in steppe succession. Particularly, this enhanced effect of biodiversity on soil stability operates via diversifying plant root traits. 
In summary, the compelling and realistic threat of global biodiversity loss has forced us to cope with biodiversity conservation issues seriously. However, these concerns may need an integrated approach and a unifying $\mathrm{BEF}$ theory that can guide conservation activities. In this regard, our findings on plant diversity and soil stability relationships over entire successions may be a good addition to currently major BEF theories and empiricisms. Indeed, incorporating both above- and below-ground patterns and processes may help form a unifying $\mathrm{BEF}$ theory that incorporates major subsystems of ecosystems and reconciles all kinds of relations amongst them.

\section{Acknowledgements}

This research was supported by the Chinese National Natural Science Foundation Program (No. 41071189), the Jilin Provincial Sci-Tech Cooperation International Program (No. 20090713) and the Jilin Provincial Personnel Affairs Services Program for Selected Sci-Tech Innovation Activities by Chinese Returnees with Overseas Study Record. Chi-Hua Huang is also thanked for hosting LJ Hu to continue this research at the USDA-ARS NSERL under a visitor program to Purdue University supported by China Scholarship Council.

\section{References}

Adler PB, Seabloom EW, Borer ET, Hillebrand H, Hautier Y, Hector A et al. (2011). Productivity is a poor predictor of plant species richness. Science 333:1750-1753.

Allan E, Weisser W, Weigelt A, Roscher C, Fischer M, Hillebrand $H$ (2011). More diverse plant communities have higher functioning over time due to turnover in complementary dominant species. PNAS 108:1-6.

Bai Y, Han X, Wu J, Chen Z, Li L (2004). Ecosystem stability and compensatory effects in the Inner Mongolia grassland. Nature 431:181-184.

Bardgett RD, Shine A (1999). Linkages between plant litter diversity, soil microbial biomass and ecosystem function in temperate grasslands. Soil Biol Biochem 31:317-321.

Bever JD (1994). Feeback between plants and their soil communities in an old field community. Ecology 75:1965-1977.

Bezemer TM, van der Putten WH (2007). Diversity and stability in plant communities. Nature 446:E6-E7.

Cammeraat E, van Beek R, Kooijman A (2005). Vegetation succession and its consequences for slope stability in SE Spain. Plant Soil 278:135-147.

Cao S (2011). Impact of China’s large-scale ecological restoration program on the environment and society in arid and semiarid areas of China: achievements, problems, synthesis, and applications. Crit Rev Environ Sci Tech 41:317-335.

De Baets S, Poesen J, Knapen A, Galindo P (2007). Impact of root architecture on the erosion-reducing potential of roots during concentrated flow. Earth Surf Proc Landforms 32:1323-1345.
De Baets S, Poesen J, Meersmans J, Serlet L (2011). Cover crops and their erosion-reducing effects during concentrated flow erosion. Catena 85:237-244.

Doak DF, Bigger D, Harding EK, Marvier MA, O’Malley RE, Thomson D (1998). The statistical inevitability of stability-diversity relationships in community ecology. Am Nat 151:264-276.

Dovciak M, Halpern CB (2010). Positive diversity-stability relationships in forest herb populations during four decades of community assembly. Ecology Lett 13:1300-1309.

Eisenhauer N, Yee K, Johnson EA, Maraun M, Parkinson D, Straube D, Scheu S (2011). Positive relationship between herbaceous layer diversity and the performance of soil biota in a temperate forest. Soil Biol Biochem 43:462-465.

Elton CS (1958). The ecology of invasions by animal and plants. University of Chicago Press, Chicago, IL.

Foster BL, Tilman D (2000). Dynamic and static views of succession: testing the descriptive power of the chronosequence approach. Plant Ecology 146:1-10.

Franzluebbers A, Wright S, Stuedemann J (2000). Soil aggregation and glomalin under pastures in the Southern Piedmont USA. Soil Sci Soc Am J 64:1018-1026.

Gastine A, Scherer-Lorenzen M, Leadley PW (2003). No consistent effects of plant diversity on root biomass, soil biota and soil abiotic conditions in temperate grassland communities. Appl Soil Ecology 24:101-111.

Gyssels G, Poesen J (2003). The importance of plant root characteristics in controlling concentrated flow erosion rates. Earth Surf Proc Landforms 28:371-384.

Haddad NM, Crustsinger GM, Gross K, Haarstaf J, Tilman D (2011). Plant diversity and the stability of foodwebs. Ecology Lett 14:42-46.

Hector A, Bagchi R (2007). Biodiversity and ecosystem multifunctionality. Nature 448:188-190.

Hedlund K, Ohrn MS (2000). Tritrophic interactions in a soil community enhance decomposition rates. Oikos 88:585591.

Heemsbergen DA, Berg MP, Loreau M, van Hal JR, Faber JH, Verhoef HA (2004). Biodiversity effects on soil processes explained by interspecific functional dissimilarity. Science 306:1019-1020.

Hooper DU, Chapin III FS, Ewel JJ, Hector A, Inchausti P, Lavorel S, Lawton JH, Lodge DM, Loreau M, NaeemS, Schmid B, Setälä H, Symstad AJ, Vandermeer J, Wardle DA (2005). Effects of biodiversity on ecosystem functioning: a consensus of current knowledge. Ecology Monogr 75:3-35.

Hooper DU, Vitousek P (1997). The effects of plant composition and diversity on ecosystem processes. Science 277:13021305.

Huston M, Smith T (1987). Plant succession: life history and competition. Am Nat 130:168-198.

Isbell FI, Polley HW, Wilsey BJ (2009). Biodiversity, productivity and the temporal stability of productivity: patterns and 
636

processes. Ecology Lett 12:443-451.

Ives AR, Carpenter SR (2007). Stability and diversity of ecosystems. Science 317:58-62.

Jiang L (2007). Density compensation can cause no effect of biodiversity on ecosystem functioning. Oikos 116:324-334.

Jiang L, Pu Z, Nemergut DR (2008). On the importance of the negative selection effect for the relationship between biodiversity and ecosystem functioning. Oikos 117:488-493.

Jiang L, Wan S, Li L (2009). Species diversity and productivity: why do results of diversity-manipulation experiments differ from natural patterns? J Ecology 97:603-608.

Lehman CL, Tilman D (2000). Biodiversity, stability, and productivity in competitive communities. Am Nat 156:534552.

Li JD (2011). China's Leymus chinensis steppe. In: Yang YF, Yang LM (eds.), Steppe vegetation ecology in NE China. Jilin Sci-Tech Press, Changchun, China.

Li JD, Guo LH (2011). The Songnen Plain Leymus chinensis steppe succession and its reclamation. In: Yang YF, Yang LM (eds.), Steppe vegetation ecology in NE China. Jilin SciTech Press, Changchun, China.

Loranger-Merciris G, Barthes L, Gastine A, Leadley P (2006). Rapid effects of plant species diversity and identity on soil microbial communities in experimental grassland ecosystems. Soil Biol Biochem 38:2336-2343.

Loreau M (2000). Biodiversity and ecosystem functioning: recent theoretical advances. Oikos 91:3-17.

Loreau M (2010). Linking biodiversity and ecosystems: towards a unifying ecological theory. Phil Trans Roy Soc B 365:4960.

Loreau M, Naeem S, Inchausti P, Bengtsson J, Grime JP, Hector A, et al. (2001). Biodiversity and ecosystem functioning: current knowledge and future challenges. Sci 294:804-808.

Luo Z, Mi X, Chen X, Ye Z, Ding B (2012). Density dependence is not very prevalent in a heterogeneous subtropical forest. Oikos 121:1239-1250.

MacArthur R (1955). Fluctuations of animal populations and a measure of community stability. Ecology 36:533-536.

Maestre FT, Quero JL, Gotelli NJ, Escudero A, Ochoa V, Delgado-Baquerizo $\mathrm{M}$ et al. (2012). Plant species richness and ecosystem multifunctionality in global drylands. Science 335:214-218

McCann KS (2000). The diversity-stability debate. Nature 405:228-233

Mouillot D, Mason WHN, Dumay O, Wilson JB (2005). Functional regularity: a neglected aspect of functional diversity. Oecologia 142:353-359.

Orwin KH, Buckland SM, Johnson D, Turner BL, Smart S, Oakley S, Bardgett RD (2010). Linkages of plant traits to soil properties and the functioning of temperate grassland. J Ecology 98:1074-1083.

Peet RK, Christensen NL (1980). Succession: a population pro- cess. Vegetatio 43:131-140.

Pfisterer AB, Schmid B (2002). Diversity-dependent production can decrease the stability of ecosystem functioning. Nature 416:84-86

Phillips J (1934). Succession, development, the climax, and the complex organism: an analysis of concepts. Part I. J Ecology 22:554-571

Pickett STA (1989). Space-for-time substitution as an alternative to long-term studies. In: Likens, G.E. (editor), Long term studies in Ecology: approaches and alternatives. SpringerVerlag, New York, USA. pp. 110-135.

Pimm SL (1984). The complexity and stability of ecosystems. Nature 307:321-326.

Pohl M, Alig D, Körner C, Rixen C (2009). Higher plant diversity enhances soil stability in disturbed alpine ecosystems. Plant Soil 324:91-102.

Pohl M, Graf F, Buttler A, Rixen C (2012). The relationship between plant species richness and soil aggregate stability can depend on disturbance. Plant Soil 355:87-102.

Porazinska D, Bardgett R, Blaauw M, Hunt H, Parsons A, Seasted T, Wall D (2003). Relationships at the abovegroundbelowground interface: plants, soil biota, and soil processes. Ecology Monogr 73:377-395.

Rajaniemi TK, Allison VJ, Goldberg DE (2003). Root competition can cause a decline in diversity with increased productivity. J Ecology 91:407-416.

Romanuk TN, Vogt RJ, Kolasa J (2009). Ecological realism and mechanisms by which diversity begets stability. Oikos 118:819-828.

Ricklefs RE (2007). History and diversity: explorations at the intersection of ecology and evolution. Am Nat 170:S56S70.

Rillig M (2004). Arbuscular mycorrhizae and terrestrial ecosystem processes. Ecology Lett 7:740-754.

Rillig MC, Caldwell BA, Wösten HAB, Sollins P (2007). Role of proteins in soil carbon and nitrogen storage: controls on persistence. Biogeochem 85:25-44.

Sankaran M, McNaughton SJ (1999). Determinants of biodiversity regulate compositional stability of communities. $\mathrm{Na}$ ture 401:691-693.

Sasaki T, Lauenroth WK (2011). Dominant species, rather than diversity, regulates temporal stability of plant communities. Oecologia 166:761-768.

Schwartz M, Brigham C, Hoeksema J, Lyons K, Mills M, Van Mantgem P (2000). Linking biodiversity to ecosystem function: implications for conservation ecology. Oecologia 122:297-305.

Sylvain ZA, Wall DH (2011). Linking soil biodiversity and vegetation: implications for a changing planet. Am J Bot 98:517-527.

Tilman D (1996). Biodiversity: population versus ecosystem stability. Ecology 77:350-363. 
Tilman D (1999). The ecological consequences of changes in biodiversity: a search for general principles. Ecology $80: 1455-1474$

Tilman D, Downing JA (1994). Biodiversity and stability in grasslands. Nature 367:363-365.

Tilman D, Knops J, Wedin D, Reich P, Ritchie M, Siemann E (1997). The influence of functional diversity and composition on ecosystem processes. Sci 277:1300-1302.

Tilman D, Lehman CL, Bristow CE (1998). Diversity-stability relationships: statistical inevitability or ecological consequence? Am Nat 151:277-282.

Tilman D, Reich PB, Knops JMH (2006). Biodiversity and ecosystem stability in a decade-long grassland experiment. Nature 441:629-632.

Tilman D, Reich PB, Knops J (2007). Replying to T.M. Bezemer and W.H. van der Putten Nature 446. doi: 10.1038/nature.

Valone TJ, Barber NA (2008). An empirical evaluation of the insurance hypothesis in diversity-stability models. Ecology 89:522-531.

Valone TJ, Hoffman CD (2003). Population stability is higher in more diverse annual plant communities. Ecology Lett 6:90-95.

van der Heijden MGA, Bardgett RD, van Straalen NM (2008). The unseen majority: soil microbes as drivers of plant diversity and productivity in terrestrial ecosystems. Ecology Lett 11:296-310.

van Ruijven J, Berendse F (2007). Contrasting effects of diversity on the temporal stability of plant populations. Oikos 116:1323-1330.

Wagg C, Jansa J, Schmid B, van der Heijden MGA (2011). Belowground biodiversity effects of plant symbionts support aboveground productivity. Ecology Lett 14:1001-1009.

Wang Z, Hou Y, Fang H, Yu D, Zhang M, Xu C, Chen M, Sun L (2012). Effects of plant species diversity on soil conservation and stability in the secondary succession phases of a semihumid evergreen broadleaf forest in China. J Soil Water Cons 67:311-320.
Wang Z, Song K, Zhang B, Liu D, Ren C, Luo L, Rena C, Luoa L, Yanga T, Huanga N, Hub L, Yangb H, Liub Z (2009). Shrinkage and fragmentation of grasslands in the West Songnen Plain, China. Agr Ecosyst Environ 129:315-324.

Wardle DA (2006). The influence of biotic interactions on soil biodiversity. Ecology Lett 9:870-886.

Wardle DA, Bonner KI, Barker GM (2000). Stability of ecosystem properties in response to above-ground functional group richness and composition. Oikos 89:11-23.

Wardle DA, Bonner KI, Nicholson KS (1997). Biodiversity and plant litter: experimental evidence which does not support the view that enhanced species richness improves ecosystem function. Oikos 79:247-258.

Wardle DA, Bardgett RD, Klironomos JN, Setälä H, van der Putten WH, Wall DH (2004). Ecological linkages between aboveground and belowground biota. Science 304:1629. 1633.

Wilson GWT, Rice CW, Rillig MC, Springer A, Hartnett DC (2009). Soil aggregation and carbon sequestration are tightly correlated with the abundance of arbuscular mycorrhizal fungi: results from long-term field experiments. Ecology Lett 12:452-461.

Yachi S, Loreau M (1999). Biodiversity and ecosystem productivity in a fluctuating environment: the insurance hypothesis. PNAS 96:1463-1468.

Yang H, Jiang L, Li L, Li A, Wu M, Wan S (2012). Diversitydependent stability under mowing and nutrient addition: evidence from a 7-year grassland experiment. Ecology Lett 15:619-626.

Zak DR, Holmes WE, White DC, Peacock AD (2003). Plant diversity, soil microbial communities, and ecosystem function: are there any links? Ecology 84:2042-2050. 